\title{
Two-way crossover comparison of insulin glargine and insulin detemir in basal-bolus therapy using continuous glucose monitoring
}

This article was published in the following Dove Press journal:

Diabetes, Metabolic Syndrome and Obesity:Targets and Therapy

12 July 201 I

Number of times this article has been viewed

\author{
Shinya Abe ${ }^{1,2}$ \\ Gaku Inoue 1,2 $^{2}$ \\ Satoru Yamada ${ }^{1,3}$ \\ Junichiro Irie ${ }^{1,3}$ \\ Hiroyuki Nojima ${ }^{2}$ \\ Kaoru Tsuyusaki \\ Kensuke Usui ${ }^{2}$ \\ Koichiro Atsuda ${ }^{2}$ \\ Toshikazu Yamanouchi ${ }^{4}$ \\ 'Diabetes Center, Kitasato Institute \\ Hospital, ${ }^{2}$ Center for Clinical \\ Pharmacy and Clinical Sciences, \\ Kitasato University, ${ }^{3}$ Department of \\ Internal Medicine, Keio University \\ School of Medicine, ${ }^{4}$ Department of \\ Internal Medicine, University of Teikyo \\ School of Medicine, Tokyo, Japan
}

Objective: This study aimed to compare the glucose-lowering effect and glycemic variability of insulin glargine with those of insulin detemir.

Material and methods: This was an open-label, single-center, randomized, two-way crossover study in patients with diabetes on basal-bolus insulin therapy, with neutral protamine Hagedorn $(\mathrm{NPH})$ insulin as basal insulin. Patients switched from NPH insulin to a course either of insulin glargine followed by insulin detemir, or insulin detemir followed by insulin glargine, continuing the same dose of the prior bolus of insulin. To evaluate the glucose-lowering effect, daily glycemic profiles were recorded for 72 hours by continuous glucose monitoring (CGM) in an outpatient setting. The mean amplitude of glycemic excursions, standard deviation (SD), and the mean of daily difference (MODD) were used to assess intraday and day-to-day glycemic variability. Results: Eleven patients were enrolled and nine completed the study. Mean blood glucose calculated from CGM values was significantly lower with insulin glargine compared with insulin detemir $(9.6 \pm 2.4 \mathrm{mmol} / \mathrm{L}$ versus $10.4 \pm 2.8 \mathrm{mmol} / \mathrm{L}, P=0.038)$. The $\mathrm{SD}$ was significantly lower with insulin glargine versus insulin detemir $(2.5 \pm 0.9 \mathrm{mmol} / \mathrm{L}$ vs $3.5 \pm 1.6 \mathrm{mmol} / \mathrm{L}$, $P=0.011)$. The MODD value was significantly lower with insulin glargine than with insulin detemir $(2.2 \pm 1.1 \mathrm{mmol} / \mathrm{L}$ vs $3.6 \pm 1.7 \mathrm{mmol} / \mathrm{L}, P=0.011)$. There was no significant difference between the two insulin analogs in terms of hypoglycemia.

Conclusion: This study suggests that insulin glargine leads to more effective and more stable glycemic control than the same dose of insulin detemir.

Keywords: continuous glucose monitoring, insulin detemir, insulin glargine

\section{Introduction}

The Diabetes Control and Complications Trial ${ }^{1}$ and the Kumamoto Study ${ }^{2}$ have shown that intensive insulin therapy and the resulting improvements in glycemic control reduce the incidence and delay the progression of microvascular complications. However, neutral protamine Hagedorn (NPH) insulin, which was used as basal insulin in these studies, has several limitations. Of note, its duration of action is only 8-12 hours, with a peak in action occurring within 4-6 hours after subcutaneous administration, thus increasing the risk of hypoglycemia. ${ }^{3-7}$ Indeed, some patients complain of hypoglycemia before dawn, necessitating a reduction in the NPH insulin dose at bedtime. However, reducing the NPH insulin dose at bedtime increases the blood glucose level in the morning. Additionally, NPH insulin is a suspension, which must be thoroughly resuspended before injection, and inadequate resuspension results in a very large day-to-day glycemic variability of action. ${ }^{8,9}$ Therefore, to achieve tight glycemic control without increasing the risk of hypoglycemia, insulin preparations with a long duration
Correspondence: Satoru Yamada Diabetes Center, Kitasato Institute Hospital, 5-9-I Shirokane, Minato-ku, Tokyo 108-8642, Japan

Tel +81334446161

Fax +8I 334480553

Email yamada-s@insti.kitasato-u.ac.jp 
of action and low day-to-day glycemic variability in terms of glucose-lowering action are needed.

Insulin glargine $e^{4,6,10}$ and insulin detemir ${ }^{5,7,11,12}$ are basal insulin analogs of the dissolution type that have flatter profiles and longer duration of action compared with NPH insulin. However, there is controversy over which insulin analog has the longer and more stable action. Therefore, in this study, the aim was to compare the glucose-lowering effect and glycemic stability of insulin glargine with those of insulin detemir using continuous glucose monitoring (CGM).

\section{Material and methods Patients}

Diabetic patients who were prescribed basal-bolus insulin therapy with NPH insulin as basal insulin at bedtime for 1 year or more were enrolled in the study. Patients who injected NPH insulin two or more times per day, with proteinuria $>1.0 \mathrm{~g} /$ day, serum creatinine $>132 \mu \mathrm{mol} / \mathrm{L}$ (men) or $106 \mu \mathrm{mol} / \mathrm{L}$ (women), abnormal aspartate aminotransferase/ alanine aminotransferase elevation $(>3 \times$ the upper limit of normal), myocardial infarction or stroke within 6 months prior to study entry, or $\mathrm{HbA}_{1 \mathrm{c}}>10.0 \%$ or $<5.8 \%$, were excluded from this study.

All patients received an explanation of the procedures and possible disadvantages of participating in the study and gave written informed consent prior to entry. This study was approved by the Institutional Review Board of Kitasato Institute Hospital and was performed in accordance with the Declaration of Helsinki.

\section{Design of the study}

Patients were randomized using a computer to either Sequence A (NPH insulin was first switched to insulin glargine, then to insulin detemir) or Sequence B (insulin detemir followed by insulin glargine). The patient's prior NPH insulin was discontinued and replaced with the allocated long-acting insulin analog (insulin glargine or insulin detemir). Patients were asked to continue their other antihyperglycemic medications and to not change their dosage throughout the study. To compare insulin glargine with insulin detemir under the same conditions, the dose of the long-acting insulin analogs was the same as that of NPH, and the doses of bolus insulin (insulin lispro or insulin aspart) were not changed. The study drugs were injected at bedtime. The CGM examination, of 72 hours in duration from 12 pm on day 1 to 12 pm on day 4 , was carried out at least 5 days after switching insulin. The study drugs were crossed over on the day when the first CGM examination ended.
The CGM sensor (CGMS ${ }^{\circledR}$ System Gold; Medtronic, Northridge, CA) was applied to the abdominal area by a certified diabetologist. Patients were instructed to measure their capillary blood glucose using finger sticks, at least four times per day (at mealtimes and at bedtime). Glucose meters were calibrated immediately before starting CGM. All patients used the CGM in outpatient settings.

\section{Glycemic control}

The outcomes of this study included determining the effectiveness of each type of insulin on glycemic control and glycemic variability. Glycemic control was estimated as the mean blood glucose (MBG), the area under the glucose curve above 7.8 or $10.0 \mathrm{mmol} / \mathrm{L}$ (area under the curve $[\mathrm{AUC}]_{>7.8,10}$ ), and the percentage of time above 7.8 or $10.0 \mathrm{mmol} / \mathrm{L}\left(\mathrm{t}_{>7.8,10}\right)$. The AUC was calculated using the trapezoidal method.

\section{Glycemic variability}

Intraday glycemic variability was assessed as the standard deviation (SD) and the mean amplitude of glycemic excursions (MAGE). The SD around the mean glucose values is considered the "gold standard" assessment of intraday glycemic variability. ${ }^{13}$ MAGE, described by Service et al, ${ }^{14}$ is probably more appropriate for selecting the major glucose swings that are calculated as the arithmetic mean of differences between consecutive peaks and nadirs, provided that the differences are greater than the SD around the mean values. $^{13}$

Day-to-day glycemic variability was assessed as the mean of daily difference (MODD). MODD, described by Molnar et al, ${ }^{15}$ is the mean of the absolute difference between glucose values taken on 2 consecutive days at the same time.

\section{Hypoglycemia}

Hypoglycemia, which was defined as a sensor value of $\leq 3.9 \mathrm{mmol} / \mathrm{L}$, was also calculated as a total time at $\leq 3.9 \mathrm{mmol} / \mathrm{L}$. Severe hypoglycemia was defined as a sensor value of $\leq 2.8 \mathrm{mmol} / \mathrm{L}$.

\section{Statistical analysis}

All values are shown as means with SD. The differences between two insulin analogs were analyzed using the Wilcoxon rank-sum test. A $P$ value of $<0.05$ was considered statistically significant. SPSS software 14.0J (SPSS Japan Inc, Tokyo, Japan) was used for all statistical analyses. 
Table I Patient demographics and baseline characteristics

Type of diabetes (type I/type 2)

Gender (male/female)

Age (years)

Diabetes duration (years)

Duration of insulin therapy (years)

Weight $(\mathrm{kg})$

BMI $\left(\mathrm{kg} / \mathrm{m}^{2}\right)$

$\mathrm{HbA}_{\mathrm{lc}}(\%)$

Fasting serum C-peptide (nmmol/L)

Total insulin dose $(\mathrm{U} / \mathrm{kg} / \mathrm{day})$

Basal insulin dose (U/kg/day)

Bolus insulin dose $(\mathrm{U} / \mathrm{kg} /$ day)

Oral glucose-lowering drugs ( $n$ )

Metformin

Alpha glucosidase inhibitor

Note: Data are mean \pm SD.

Abbreviations: BMI, body mass index; $\mathrm{Hb}$ Alc, hemoglobin Alc.

\section{Results}

\section{Patient characteristics}

A total of eleven Japanese patients, six with type 1 and five with type 2 diabetes, were enrolled between May 2008 and June 2009. Because of an alert for insulin glargine issued by the European Association for the Study of Diabetes, ${ }^{16}$ this study was discontinued and the available data was analyzed. Two patients were excluded from analysis because of protocol violation (misuse of NPH). Therefore, nine patients (five in Sequence A and four in Sequence B) completed the study. The demographic and baseline characteristics of these patients are shown in Table 1.

\section{Glycemic control}

MBG, as calculated from CGM values, was significantly lower with insulin glargine than with insulin detemir $(9.6 \pm 2.4 \mathrm{mmol} / \mathrm{L}$ versus $10.4 \pm 2.8 \mathrm{mmol} / \mathrm{L}, P=0.038)$ (type 1: $11.0 \pm 2.5 \mathrm{mmol} / \mathrm{L}$ versus $12.2 \pm 2.7 \mathrm{mmol} / \mathrm{L}$; type 2 : $8.4 \pm 1.8 \mathrm{mmol} / \mathrm{L}$ versus $9.0 \pm 2.2 \mathrm{mmol} / \mathrm{L})$. Figure 1 shows the mean daily profiles of day 2 and day 3. This difference between the two insulin analogs was particularly evident at nighttime. In addition, $\mathrm{AUC}_{>10}$ and $\mathrm{AUC}_{>7.8}$ were significantly lower with insulin glargine versus insulin detemir (Table 2).

\section{Glycemic variability}

The SD was significantly lower with insulin glargine than with insulin detemir. However, the MAGE value was not significantly different between the two insulin analogs (Table 3). The MODD value was significantly lower with insulin glargine than with insulin detemir (2.2 $\pm 1.1 \mathrm{mmol} / \mathrm{L}$ vs $3.6 \pm 1.7 \mathrm{mmol} / \mathrm{L}, P=0.011$; Figure 2$)$ (type $1: 2.7 \pm 1.2 \mathrm{mmol} / \mathrm{L}$ vs $4.7 \pm 1.8 \mathrm{mmol} / \mathrm{L}$; type 2 : $1.8 \pm 0.9 \mathrm{mmol} / \mathrm{L}$ vs $2.7 \pm 0.9 \mathrm{mmol} / \mathrm{L})$.

\section{Hypoglycemia}

There was no difference between the two insulin analogs in terms of the total hypoglycemic time. This lack of a difference remained even after separating the results according to daytime and nighttime values. Severe hypoglycemic time was also similar for both insulin analogs (Table 2).

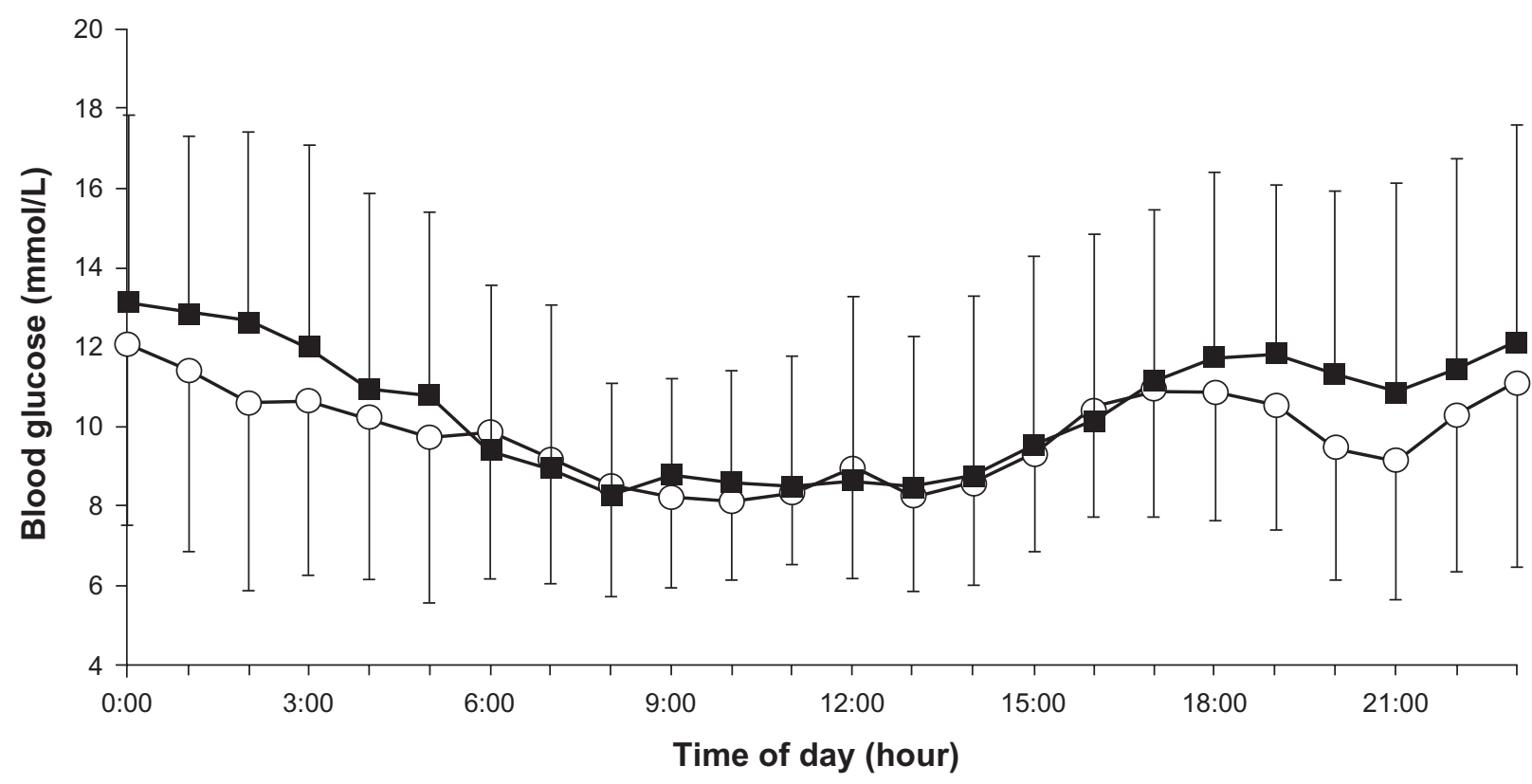

Figure I 24-hour glucose profiles of day 2 and day 3. Each point represents the mean \pm standard deviation of nine patients treated with insulin glargine $(O)$ or detemir $(\square)$. 
Table 2 Comparison of glargine CGM data with detemir CGM data

\begin{tabular}{|c|c|c|c|}
\hline & Glargine & Detemir & $P$ value \\
\hline \multicolumn{4}{|l|}{ Glycemic control } \\
\hline $\mathrm{MBG}(\mathrm{mmol} / \mathrm{L})$ & $9.6 \pm 2.4$ & $10.4 \pm 2.8$ & 0.038 \\
\hline Type I & $11.0 \pm 2.5$ & $12.2 \pm 2.7$ & ns \\
\hline Type 2 & $8.4 \pm 1.8$ & $9.0 \pm 2.2$ & ns \\
\hline $\mathrm{AUC}_{>10}(\mathrm{mmol} / \mathrm{L} /$ day $)$ & $1.2 \pm 1.5$ & $2.1 \pm 2.0$ & 0.011 \\
\hline Type I & $2.1 \pm 1.7$ & $3.5 \pm 1.9$ & 0.068 \\
\hline Type 2 & $0.5 \pm 0.9$ & $1.0 \pm 1.3$ & 0.080 \\
\hline $\mathrm{AUC}_{>7.8}(\mathrm{mmol} / \mathrm{L} /$ day $)$ & $2.4 \pm 2.1$ & $3.3 \pm 2.5$ & 0.008 \\
\hline Type I & $3.6 \pm 2.2$ & $5.0 \pm 2.3$ & 0.068 \\
\hline Type 2 & $1.4 \pm 1.5$ & $2.0 \pm 1.7$ & 0.043 \\
\hline $\mathrm{t}_{>10}(\%)$ & $37.6 \pm 31.4$ & $44.3 \pm 28.6$ & 0.051 \\
\hline Type I & $57.2 \pm 26.3$ & $61.7 \pm 24.4$ & ns \\
\hline Type 2 & $21.9 \pm 27.6$ & $30.5 \pm 25.5$ & 0.080 \\
\hline $\mathrm{t}_{>7.8}(\%)$ & $61.9 \pm 24.1$ & $63.8 \pm 21.1$ & ns \\
\hline Type I & $75.1 \pm 19.2$ & $72.3 \pm 19.1$ & ns \\
\hline Type 2 & $51.4 \pm 23.9$ & $57.1 \pm 22.0$ & ns \\
\hline \multicolumn{4}{|l|}{ Hypoglycemic } \\
\hline \multicolumn{4}{|c|}{ Total hypoglycemic $\left(\mathrm{t}_{<3.9}\right)$ time $(\mathrm{min})$} \\
\hline Overtime & $64 \pm 81$ & $97 \pm 177$ & ns \\
\hline Type I & $94 \pm 89$ & $65 \pm 60$ & ns \\
\hline Type 2 & $40 \pm 74$ & $|22 \pm 24|$ & ns \\
\hline Nighttime & $42 \pm 74$ & $19 \pm 48$ & ns \\
\hline Type I & $83 \pm 99$ & $43 \pm 69$ & ns \\
\hline Type 2 & $10 \pm 22$ & $0 \pm 0$ & ns \\
\hline \multicolumn{4}{|c|}{ Severe hypoglycemic $\left(\mathrm{t}_{<2.8}\right)$ time $(\mathrm{min})$} \\
\hline Overtime & $18 \pm 49$ & $6 \pm 11$ & ns \\
\hline Type I & $38 \pm 75$ & $11 \pm 16$ & ns \\
\hline Type 2 & $3 \pm 4$ & $2 \pm 4$ & ns \\
\hline Nighttime & $17 \pm 50$ & $16 \pm 48$ & ns \\
\hline Type I & $38 \pm 75$ & $36 \pm 73$ & ns \\
\hline Type 2 & $0 \pm 0$ & $0 \pm 0$ & ns \\
\hline
\end{tabular}

Note: Data are mean \pm SD.

Abbreviations: MBG, mean blood glucose; AUC, area under the curve; CGM, continuous glucose monitoring; ns, not significant.

\section{Discussion}

In this study, the glucose-lowering effect and glucose stability of insulin glargine was compared with those of insulin detemir using CGM. Glycemic control parameters, such as $\mathrm{MBG}, \mathrm{AUC}_{>10}$, and $\mathrm{AUC}_{>7.8}$, were better with insulin glargine than with insulin detemir. The present study suggests that insulin glargine has a greater glucose-lowering effect than insulin detemir at the same dose. The difference in glucose-lowering effect can be compensated for by increasing the insulin dose but there might be a difference in the cost-effectiveness and hypoglycemic episode. Because the same tendency was found in both type 1 and type 2 diabetes (MBG in type 1: insulin glargine, $11.0 \pm 2.5 \mathrm{mmol} / \mathrm{L}$ versus insulin detemir, $12.2 \pm 2.7 \mathrm{mmol} / \mathrm{L}$; type $2: 8.4 \pm 1.8 \mathrm{mmol} / \mathrm{L}$ versus $9.0 \pm 2.2 \mathrm{mmol} / \mathrm{L}$ ), to maintain statistical power, the two types of diabetes were not distinguished.
Table 3 Comparison of the intraday glycemic variability of glargine with that of detemir

\begin{tabular}{llcl}
\hline & Glargine & Detemir & $P$ value \\
\hline SD $(\mathrm{mmol} / \mathrm{L})$ & $2.5 \pm 0.9$ & $3.5 \pm 1.6$ & $0.01 \mathrm{I}$ \\
Type I & $3.2 \pm 0.8$ & $4.6 \pm 1.6$ & $0.08 \mathrm{I}$ \\
Type 2 & $2.0 \pm 0.6$ & $2.6 \pm 1.0$ & $\mathrm{~ns}$ \\
MAGE $(\mathrm{mmol} / \mathrm{L})$ & $6.3 \pm 2.4$ & $7.8 \pm 3.6$ & 0.086 \\
Type I & $7.8 \pm 1.7$ & $10.1 \pm 3.4$ & $\mathrm{~ns}$ \\
Type 2 & $5.1 \pm 2.2$ & $5.9 \pm 2.7$ & $\mathrm{~ns}$ \\
MODD (mmol/L) & $2.2 \pm 1.1$ & $3.6 \pm 1.7$ & $0.01 \mathrm{I}$ \\
Type I & $2.7 \pm 1.2$ & $4.7 \pm 1.8$ & $\mathrm{~ns}$ \\
Type 2 & $1.8 \pm 0.9$ & $2.7 \pm 0.9$ & $\mathrm{~ns}$ \\
\hline
\end{tabular}

Note: Data are mean \pm SD.

Abbreviations: MAGE, mean amplitude of glycemic excursions; MODD, mean of daily difference; $\mathrm{ns}$, not significant.

However, the hypoglycemic time was comparable for both of the two insulin analogs. These findings suggest that, if higher doses of insulin detemir are administered to achieve equivalent glycemic control to insulin glargine, the hypoglycemic time might increase.

Furthermore, the intraday and day-to-day glycemic variability of insulin glargine was compared with those of insulin detemir. The results of CGM revealed that SD and MODD were lower with insulin glargine than with insulin detemir. These findings suggest that insulin glargine might have better glycemic variability compared with insulin detemir. It is expected that the risk of hypoglycemia is lower with insulin glargine than with insulin detemir, if the aim of treatment is near-normal glycemia.

Several previous studies have compared insulin glargine with insulin detemir. ${ }^{17-29}$ Three studies using insulin-clamp tests yielded very conflicting results. ${ }^{17-19}$ Heise et al reported that the same doses $(0.4 \mathrm{U} / \mathrm{kg})$ of insulin glargine and insulin detemir are very similar in terms of the mean shape of their

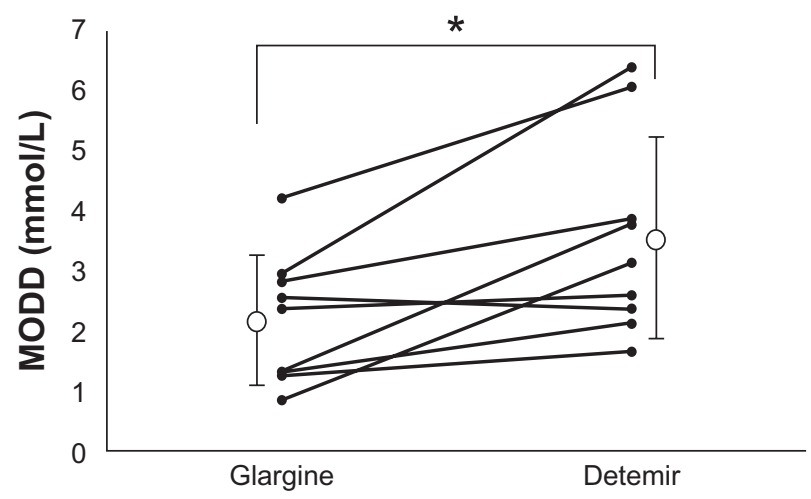

Figure 2 Comparison of the mean of daily difference (MODD) in nine patients treated with insulin glargine or detemir. The MODD value was significantly lower with insulin glargine than with insulin detemir.

Note: $* P=0.011$. 
pharmacodynamic profiles and duration of action in patients with type 1 diabetes. ${ }^{17}$ They also reported that the day-to-day glycemic variability is lower with insulin detemir. Klein et al reported a similar duration of action and lower day-to-day glycemic variability with insulin detemir versus insulin glargine in patients with type 2 diabetes $(0.8-1.6 \mathrm{U} / \mathrm{kg}){ }^{18}$ By contrast, Porcellati et al reported that $0.35 \mathrm{U} / \mathrm{kg}$ of insulin detemir has similar effects to the same dose of insulin glargine during the first 12 hours, and that the metabolic effects of insulin detemir are lower at 12-24 hours. ${ }^{19}$

Six clinical studies have compared insulin glargine with insulin detemir. In five studies, in which all patients or more than half of the patients were injected with insulin detemir twice daily, glycemic control was similar to that of once-daily insulin glargine. ${ }^{20-24}$ The other study, in which the majority $(87.4 \%)$ of patients were injected with insulin detemir once a day, suggested inferiority of glycemic control for insulin detemir versus once-daily insulin glargine. ${ }^{25}$

These clinical studies clearly showed that, at similar daily doses, insulin detemir has a shorter action time and weaker action than insulin glargine. These findings are consistent with the results of the present study and with the results of a clamp study reported by Porcellati et al. ${ }^{19}$

Tone et al compared the day-to-day glycemic variability of insulin glargine with that of insulin detemir. ${ }^{26}$ However, CGM was not used and the study evaluated only fasting plasma glucose; therefore, the study was inconclusive. However, King et al and Wiesli et al have reported comparisons of insulin glargine with insulin detemir using CGM. Although these studies concluded that once-daily insulin detemir provided 24-hour glycemic control similar to that of insulin glargine in patients with type 2 diabetes, did glycemic variability was not reported. ${ }^{27-29}$ To the best of the present authors' knowledge, the present study is the first to show that insulin glargine has better glycemic variability than insulin detemir based on CGM.

There are several limitations to this study. First, because of the alert for insulin glargine, it was deemed inappropriate to continue enrolling patients to receive insulin glargine. Therefore, the number of subjects enrolled was too small to reach a definitive conclusion and patients with type 1 and type 2 diabetes were combined. However, as shown in Figure 2, most of the patients had lower MODD values with insulin glargine than with insulin detemir. In fact, our finding of lower MODD was consistent after stratification for the type of diabetes (insulin glargine versus insulin detemir, type $1: 2.7 \pm 1.2 \mathrm{mmol} / \mathrm{L}$ versus $4.7 \pm 1.8 \mathrm{mmol} / \mathrm{L}$; type 2 : $1.8 \pm 0.9 \mathrm{mmol} / \mathrm{L}$ versus $2.7 \pm 0.9 \mathrm{mmol} / \mathrm{L}$ ). Therefore, the authors' believe this conclusion may be robust. Second, the doses of basal insulin used in the present study were different from those used in the earlier clinical studies. The average basal insulin dose was $0.24 \mathrm{U} / \mathrm{kg} /$ day in this study (type 1 : $0.22 \mathrm{U} / \mathrm{kg} /$ day; type $2: 0.26 \mathrm{U} / \mathrm{kg} /$ day), which was much lower than in earlier clinical studies (insulin glargine: $0.33^{21}$ $0.75^{25} \mathrm{U} / \mathrm{kg} /$ day; insulin detemir: $0.40^{21}-0.82^{23} \mathrm{U} / \mathrm{kg} /$ day). However, these studies were performed in European countries or in the USA. The doses of basal insulin used in our study are similar to those used in the Japanese national phase III program for insulin glargine for Japanese patients with type 1 diabetes (mean: $0.21 \mathrm{U} / \mathrm{kg} / \mathrm{day})^{30}$ and insulin detemir for Japanese patients with type 1 or type 2 diabetes (mean: $0.27 \mathrm{U} / \mathrm{kg} / \mathrm{day}$ ). ${ }^{31}$ Therefore, the insulin dose in the present study appears to be appropriate for Japanese patients.

\section{Conclusion}

The results of the present study suggest that insulin glargine provides more effective and more stable glycemic control than insulin detemir. Because this study was too small to make a final conclusion, however, large-scale studies are required to confirm these findings.

\section{Disclosure}

The authors report no conflicts of interest in this work.

\section{References}

1. Diabetes Control and Complications Trial (DCCT) Research Group. The effect of intensive treatment of diabetes on the development and progression of long-term complications in insulin-dependent diabetes mellitus. N Engl J Med. 2003;329:977-986.

2. Ohkubo Y, Kishikawa $\mathrm{H}$, Araki E, et al. Intensive insulin therapy prevents the progression of diabetic microvascular complications in Japanese patients with non-insulin-dependent diabetes mellitus. Diabetes Res Clin Pract. 1995;28:103-117.

3. Hirsch IB. Insulin analogues. N Engl J Med. 2005;352:174-183.

4. Lepore M, Pampanelli S, Fanelli C, et al. Pharmacokinetics and pharmacodynamics of subcutaneous injection of long-acting human insulin analog glargine, NPH insulin, and ultralente human insulin and continuous subcutaneous infusion of insulin lispro. Diabetes. 2000;49:2142-2148.

5. Plank J, Bodenlenz M, Sinner F, et al. A double-blind, randomized, doseresponse study investigating the pharmacodynamic and pharmacokinetic properties of the long-acting insulin analog detemir. Diabetes Care. 2005; 28:1107-1112.

6. Heinemann L, Linkeschova R, Rave K, Hompesch B, Sedlak M, Heise T. Time-action profile of the long-acting insulin analog insulin glargine (HOE901) in comparison with those of NPH insulin and placebo. Diabetes Care. 2000;23:644-649.

7. Fanelli GC, Pampanelli S, Porcellati F, Rossetti P, Brunetti P, Bolli GB. Administration of neutral protamine Hagedorn insulin at bedtime versus dinner in type 1 diabetes mellitus to avoid nocturnal hypoglycemia and improve control. A randomized, controlled trial. Ann Intern Med. 2002;136:504-514.

8. Jehle PM, Micheler C, Jehle DR, Breitig D, Boehm BO. Inadequate suspension of neutral protamine Hagedorn (NPH) insulin in pens. Lancet. 1999;354:1604-1607. 
9. Kølendorf K, Bojsen J, Deckert T. Clinical factors influencing the absorption of ${ }^{125} \mathrm{I}-\mathrm{NPH}$ insulin in diabetic patients. Horm Metab Res. 1983;15:274-278.

10. Wang F, Carabino JM, Vergara CM. Insulin glargine: a systematic review of a long-acting insulin analogue. Clin Ther. 2003;25:1541-1577.

11. Kurtzhals P, Havelund S, Jonassen I, et al. Albumin binding of insulins acylated with fatty acids: characterization of the ligand-protein interaction and correlation between binding affinity and timing of the insulin effect in vivo. Biochem J. 1995;312:725-731.

12. Havelund S, Plum A, Ribel U, et al. The mechanism of protraction of insulin detemir, a long-acting, acylated analog of human insulin. Pharm Res. 2004;21:1498-1504.

13. Monnier L, Colette C, Owens DR. Glycemic variability: the third component of the dysglycemia in diabetes. Is it important? How to measure it? J Diabetes Sci Technol. 2008;2:1094-1100.

14. Service FJ, Molnar GD, Rosevear JW, Ackerman E, Gatewood LC, Taylor WF. Mean amplitude of glycaemic excursions, a measure of diabetic instability. Diabetes. 1970;19:644-655.

15. Molnar GD, Taylor WF, Ho MM. Day-to-day variation of continuously monitored glycaemia: a further measure of diabetic instability. Diabetologia. 1972;8:342-348.

16. Hemkens LG, Grouven U, Bender R, et al. Risk of malignancies in patients with diabetes treated with human insulin or insulin analogues: a cohort study. Diabetologia. 2009;52:1732-1744.

17. Heise T, Nosek L, Ronn BB, et al. Lower within-subject variability of insulin detemir in comparison to NPH insulin and insulin glargine in people with type 1 diabetes. Diabetes. 2004;53:1614-1620.

18. Klein O, Lynge J, Endahl L, Damholt B, Nosek L, Heise T. Albuminbound basal insulin analogues (insulin detemir and NN344): comparable time-action profiles but less variability than insulin glargine in type 2 diabetes. Diabetes Obes Metab. 2007;9:290-299.

19. Porcellati F, Rossetti P, Busciantella NR, et al. Comparison of pharmacokinetics and dynamics of the long-acting insulin analogs glargine and detemir at steady state in type 1 diabetes: a double-blind, randomized, crossover study. Diabetes Care. 2007;30:2447-2452.

20. Rosenstock J, Davies M, Home PD, Larsen J, Koenen C, Schernthaner G. A randomized, 52 week, treat-to-target trial comparing insulin detemir with insulin glargine when administered as add-on to glucose-lowering drugs in insulin-naïve people with type 2 diabetes. Diabetologia. 2008; 51:408-416.

21. Heller S, Koenen C, Bode B. Comparison of insulin detemir and insulin glargine in a basal-bolus regimen, with insulin aspart as the mealtime insulin, in patients with type 1 diabetes: a 52-week, multinational, randomized, open-label, parallel-group, treat-to-target noninferiority trial. Clin Ther. 2009;31:2086-2097.
22. Pieber TR, Treichel HC, Hompesch B, et al. Comparison of insulin detemir and insulin glargine in subjects with Type 1 diabetes using intensive insulin therapy. Diabet Med. 2007;24:635-642.

23. Hollander P, Cooper J, Bregnhøj J, Pedersen CB. A 52-week, multinational, open-label, parallel-group, noninferiority, treat-to-target trial comparing insulin detemir with insulin glargine in a basal-bolus regimen with mealtime insulin aspart in patients with type 2 diabetes. Clin Ther. 2008;30:1976-1987.

24. Swinnen SG, Dain MP, Aronson R, et al. A 24-week, randomized, treat-to-target trial comparing initiation of insulin glargine once-daily with insulin detemir twice-daily in patients with type 2 diabetes inadequately controlled on oral glucose-lowering drugs. Diabetes Care. 2010;33:1176-1178.

25. Raskin P, Gylvin T, Weng W, Chaykin L. Comparison of insulin detemir and insulin glargine using a basal-bolus regimen in a randomized, controlled clinical study in patients with type 2 diabetes. Diabetes Metab Res Rev. 2009;25:542-548.

26. Tone A, Iseda I, Higuchi C, et al. Comparison of insulin detemir and insulin glargine on glycemic variability in patients with type 1 and type 2 diabetes. Exp Clin Endocrinol Diabetes. 2010;118:320-324.

27. King AB. Once-daily insulin detemir is comparable to once-daily insulin glargine in providing glycaemic control over $24 \mathrm{~h}$ in patients with type 2 diabetes: a double-blind, randomized, crossover study. Diabetes Obes Metab. 2009;11:69-71.

28. King $\mathrm{AB}$. No higher dose requirements with insulin detemir than glargine in type 2 diabetes: a crossover, double-blind, and randomized study using continuous glucose monitoring. J Diabetes Sci Technol. 2010;4:151-154.

29. Wiesli P, Krayenbuhl P, Uthoff H, Seifert B, Schmid C. Omitting breakfast and lunch after injection of different long-acting insulin preparations at bedtime: a prospective study in patients with type 2 diabetes. Diabetologia. 2009;52:1816-1819.

30. Kawamori R, Iwamoto Y, Kadowaki T, Iwasaki M. Comparison of efficacy between insulin glargine and NPH human insulin in type 1 diabetes patients undergoing intensive insulin treatment - phase II/III clinical studies in Japan [in Japanese]. Rinsho Iyaku. 2003;19:423-440.

31. Kobayashi M, Iwamoto Y, Kaku K, Kawamori R, Tajima N. 48-week randomized multicenter open-label parallel group phase 3 trial to compare insulin detemir and NPH insulin efficacy and safety in subjects with insulin requiring diabetes mellitus in a basal-bolus regimen [in Japanese]. J Japan Diab Soc. 2007;50:649-663.

\section{Publish your work in this journal}

Diabetes, Metabolic Syndrome and Obesity: Targets and Therapy is an international, peer-reviewed open-access journal committed to the rapid publication of the latest laboratory and clinical findings in the fields of diabetes, metabolic syndrome and obesity research. Original research, review, case reports, hypothesis formation, expert opinion and commentaries are all considered for publication. The manuscript management system is completely online and includes a very quick and fair peer-review system, which is all easy to use. Visit http://www.dovepress.com/testimonials.php to read real quotes from published authors. 